\title{
Asthma in children exposed to nitrogen dioxide in ice arenas
}

\author{
P. Thunqvist*,\#, G. Lilja"\#, M. Wickman", , G. Pershagen*,
}

\begin{abstract}
Asthma in children exposed to nitrogen dioxide in ice arenas. P. Thunqvist, G. Lilja, M. Wickman, G. Pershagen. (C) ERS Journals Ltd 2002.

ABSTRACT: Very high concentrations of nitrogen dioxide $\left(\mathrm{NO}_{2}\right)$ have been measured in arenas using combustion engine-powered resurfacing machines. This study was performed to compare the occurrence of asthma in children playing ice hockey in arenas using propane-powered machines and in children attending arenas using electric machines.
\end{abstract}

Children regularly playing hockey in the arenas (nine propane, six electric) were sent a questionnaire, including questions on allergic disease and risk factors. Measurements of $\mathrm{NO}_{2}$ were performed with passive diffusion samplers during 3 consecutive days.

The mean $\mathrm{NO}_{2}$ concentration in the propane arenas was $276 \mu \mathrm{g} \cdot \mathrm{m}^{-3}$ (range $\left.28-1015 \mu \mathrm{g} \cdot \mathrm{m}^{-3}\right)$ and $11 \mu \mathrm{g} \cdot \mathrm{m}^{-3}(2-30)$ in the electric arenas. Questionnaires were answered by 1,536 children $(78 \%)$, with an overall prevalence of asthma of $16 \%$. The odds ratio (OR) for asthma was $0.9(95 \%$ confidence interval $(\mathrm{CI}) 0.7-1.2)$ comparing propane arenas to electric. However, children in propane arenas with higher than median concentration of $\mathrm{NO}_{2}$ reported more wheezing (OR 1.4, 95\% CI 1.0-1.9) and nasal symptoms (OR 1.7, 95\% CI 1.3-2.3) than children in propane arenas with lower concentrations.

In conclusion, children playing ice hockey in indoor arenas have a high prevalence of asthma, but it appears unlikely that increased exposure to combustion products, including nitrogen dioxide, is a major contributor to this excess risk.

Eur Respir J 2002; 20: 646-650.

\author{
*Institute of Environmental Medi- \\ cine, and "Sachs' Children's Hospital, \\ Sodersjukhuset, Karolinska Institutet, \\ and Dept of Environmental Health, \\ Stockholm County Council, Stock- \\ holm, Sweden. \\ Correspondence: P. Thunqvist, Insti- \\ tute of Environmental Medicine, \\ Karolinska Institutet, Box 210, SE - \\ 17177 Stockholm, Sweden. \\ Fax: 468304571 \\ E-mail: per.thunqvist@ \\ sachsska.sos.sll.se
}

Keywords: Asthma, ice hockey, indoor ice arena, nitrogen dioxide, rhinitis

Received: August 122001

Accepted after revision: December 25 2001

This study was supported by grants from the Swedish Foundation of Strategic and Environmental Research (MISTRA) and the Asthma and Allergy Association of Sweden.
Long-term exposure to ambient air pollution and its potential effect on the development of asthma and atopy has been a topic of interest in recent years. Some authors report an association between increased exposure to air pollution, with nitrogen dioxide $\left(\mathrm{NO}_{2}\right)$ as a major component, and respiratory tract illness as well as atopy in children, but the evidence is not consistent [1-5]. In these studies the contrast in exposure to $\mathrm{NO}_{2}$ between study subjects was limited and together with potential confounding this makes the results difficult to interpret.

High concentrations of $\mathrm{NO}_{2}$ may occur in ice arenas when propane- or gasoline-powered iceresurfacing machines are used [6]. Outbreaks of respiratory illness have been reported after exposure to very high concentrations of $\mathrm{NO}_{2}$ in ice arenas, i.e. in the order of several thousands of $\mu \mathrm{g} \cdot \mathrm{m}^{-3}$, probably due to malfunctioning of combustion engines and poor ventilation [7, 8]. In follow-up investigations after such accidents no long-term health effects have been demonstrated [7, 8]. However, there is a lack of studies on long-term effects of regular exposure to high $\mathrm{NO}_{2}$ concentrations in ice arenas.

The aim of this study was to assess the risk of bronchial asthma for children playing ice hockey or figure skating in indoor ice arenas with propane-powered ice-resurfacing machines compared to a group of children primarily attending arenas with electricpowered machines.

\section{Material and methods}

\section{Area and arenas}

In the planning of this study a survey of all 286 Swedish indoor ice arenas was made in 1998. This showed that two thirds of the arenas used propanepowered ice-resurfacing machines. Based on this survey a region in the central part of Sweden with a large number of indoor ice arenas was selected. The region consists of small communities and rural areas except for the city of Gävle, which has $\sim 67,000$ inhabitants. Thus, 15 arenas at 14 different locations were included, nine using propane-powered and six using electric-powered machines. Two of the electricpowered arenas were located in the city of Gävle.

\section{Study population}

All children in hockey and figure-skating clubs in Sweden are registered from the age of 10 in a mandatory insurance file. From this file it was possible 
to identify 2,231 children, aged $10-16$ yrs who were presently active in clubs using the selected arenas or had been active during any of the 3 yrs prior to the study. In the winter of 1999 a questionnaire was sent to the selected children and their parents. The response rate following two postal reminders was $77.8 \%$, similar for children attending electric-powered and propane-powered arenas. One hundred and nine of the children who attended electric arenas reported that their main activity was on outdoor rinks and were excluded from analysis. Furthermore, children in electric arenas with mixed exposure to both types of resurfacing machines were also excluded, leaving a total of 1,535 children for the final analysis.

\section{Questionnaire and health outcome measurements}

The questionnaire had 57 questions, including 10 on symptoms of atopic diseases identical to those in the International Study of Asthma and Allergies in Childhood (ISAAC-1) for children aged 13-14 yrs [9]. Furthermore, questions on "physician-diagnosed asthma" and asthma medication were added. To estimate the exposure to $\mathrm{NO}_{2}$, questions on physical exercise in ice arenas, training intensity and use of more than one arena were included. Questions on living conditions, household pets (past and present), household smoking (past and present) and parental history of allergic disease were also included. The parents were given instructions to complete the questionnaire together with their child.

\section{Nitrogen dioxide monitoring}

At the time of distribution of the questionnaires ambient $\mathrm{NO}_{2}$ was measured inside and outside all the selected arenas. In addition to the propane- or electric-powered resurfacing machines, all arenas used ice edgers powered by combustion engines. The resurfacing machines were used daily on average $\sim 1 \mathrm{~h}$ and the edgers were usually used once or twice a week for $\sim 15 \mathrm{~min}$. The measurements were started on the day before the "special ice-care day", when the resurfacing machine was operated for a longer time and the edger was used. $\mathrm{NO}_{2}$ concentrations were determined by passive diffusion samplers at three different locations in each arena during 3 consecutive days. Each sampler was in use for 1 day only. At each arena two samplers were located near the rink (goal and rink-side) and one outside.

The samplers were in position during open hours, usually $13 \mathrm{~h} \cdot$ day $^{-1}$. To control for passive diffusion of $\mathrm{NO}_{2}$ into the sampler when not used, a control sampler not removed from its sealed tube was used during all 3 days in each arena. The sampler was developed by the Swedish Environment Research Institute and gives time integrated $\mathrm{NO}_{2}$ concentrations [10]. The relative SD between duplicate samplers has been estimated as $<4 \%$ and the concentrations are within $\pm 15 \%$ of those obtained by volumetric techniques.

\section{Statistical analysis}

Comparisons between children exposed to propanepowered and electric-powered resurfacing machines were performed by estimating odds ratios (OR) and 95\% confidence intervals (CI), using logistic regression analysis. Adjustment was made for sex and family history of allergic disease. Other potential confounders, such as keeping furred pets, a smoking mother or condensation on window panes during wintertime, did not influence the OR and were not included in the regression models. Individuals not responding to a particular question were excluded from analysis of that question. However, missing values were $\leqslant 1 \%$ in any single question.

\section{Ethical considerations}

The Ethics Committee of Karolinska Institute, Stockholm, Sweden, approved the study and all families gave informed consent before participation.

\section{Results}

\section{Exposure and demographic data}

Of the 1,535 children in the final analysis, 969 practised in propane arenas and 566 in electric arenas. The study group included 1,470 (95.8\%) males and $65(4.2 \%)$ females, with an average age of $13 \mathrm{yrs}$ (range 9-16). Data on exposure to $\mathrm{NO}_{2}$, demographic characteristics and potential risk factors for allergy among the participating children are presented in table 1 . The age and sex distribution as well as training history were similar in the two groups of children. Most children had $>3$ yrs of activity in the ice arenas and $79 \%$ (propane arenas) and $76 \%$ (electric arenas)

Table 1.-Demographic data and potential risk factors for asthma in children attending ice arenas with either propane-powered or electric-powered ice-resurfacing machines

\begin{tabular}{|c|c|c|}
\hline & Propane & Electric \\
\hline Male & $932(96.2)$ & $537(95.0)$ \\
\hline Age $9-11$ yrs & $227(23.4)$ & $144(25.6)$ \\
\hline Age $12-13$ yrs & $344(35.5)$ & $218(38.5)$ \\
\hline Age $14-16$ yrs & $398(41.1)$ & 203 (35.9) \\
\hline Presently active in ice arenas & 771 (79.6) & $434(76.7)$ \\
\hline$>3$ Yrs of activity in ice arenas & $835(86.2)$ & $461(81.5)$ \\
\hline $\begin{array}{l}\text { Parental history of } \\
\text { asthma or atopy }\end{array}$ & $375(38.7)$ & $237(41.9)$ \\
\hline Reported atopy & $205(21.2)$ & $135(23.8)$ \\
\hline Smoking mother & $210(21.7)$ & $113(20.0)$ \\
\hline Indoor smoking at any time & $186(19.2)$ & $115(20.3)$ \\
\hline Present household pets ${ }^{+}$ & $338(34.9)$ & $201(35.5)$ \\
\hline Increased humidity at home $\mathrm{e}^{\S}$ & $252(26.0)$ & $147(25.9)$ \\
\hline
\end{tabular}

Data are presented as $\mathrm{n}(\%){ }^{\#}$ : reported allergy to pollens or furred pets (cat, dog); : household member smoking indoors at present or at any time after the birth of the child; ${ }^{+}$: furred pets (cat, dog); ${ }^{\text {: }}$ : reported condensation on window panes during wintertime. 
Table 2. - Concentration of nitrogen dioxide $\left(\mathrm{NO}_{2}\right)\left(\mu \mathrm{g} \cdot \mathrm{m}^{-3}\right)$ during 3 consecutive days in and outside 15 ice arenas with either propane- or electric-powered resurfacing machines $^{\#}$

\begin{tabular}{|c|c|c|}
\hline & Propane & Electric \\
\hline Subjects $\mathrm{n}$ & 9 & 6 \\
\hline \multicolumn{3}{|l|}{ Day 1} \\
\hline Indoor & $238(171,28-978)$ & $11(11,3-17)$ \\
\hline Outdoor & $12(11,3-30)$ & $9(4,2-24)$ \\
\hline \multicolumn{3}{|l|}{ Day 2} \\
\hline Indoor & $297(190,43-819)$ & $9(4,2-24)$ \\
\hline Outdoor & $10(9,3-29)$ & $24(24,16-31)$ \\
\hline \multicolumn{3}{|l|}{ Day 3} \\
\hline Indoor & $293(187,45-1016)$ & $8(8,1-20)$ \\
\hline Outdoor & $11(9,0-28)$ & $16(11,11-26)$ \\
\hline \multicolumn{3}{|l|}{ Total } \\
\hline Indoor & $276(190)$ & $11(9)$ \\
\hline Outdoor & $11(10)$ & $16(14)$ \\
\hline
\end{tabular}

Data are presented as mean (median, range) unless otherwise stated. ${ }^{\#}$ : the samplers were in position during open hours, usually $13 \mathrm{~h} \cdot \mathrm{day}^{-1}$. For each day of measurement a new sampler was used in each position.

were still active in the winter of 1999 when the present study was performed. Of the 328 children who had stopped sport activities in ice arenas during the last 3 yrs, change of sports was reported as the main reason $(78 \%)$. This was equally distributed between the two groups. However, 10 children reported breathing problems when attending ice arenas (four propane, six electric) as the major cause. There was no significant difference in potential risk factors for bronchial asthma between groups, such as housing conditions, indoor dampness, parental smoking (past or present) or keeping furred pets (past or present). However, children in the electric-arena group tended to have a higher prevalence of parental history of asthma and atopy $(41.9 \%)$ than children in the propane-arena group $(38.7 \%)$.

\section{Nitrogen dioxide monitoring}

The results from $\mathrm{NO}_{2}$ measurements are presented in table 2. There was a wide range of $\mathrm{NO}_{2}$ concentrations in the nine propane arenas $\left(28-1,015 \mu \mathrm{g} \cdot \mathrm{m}^{-3}\right)$.
The measurements were consistent within the arenas, i.e. the range of $\mathrm{NO}_{2}$ was small in each arena. The same arena had the lowest concentrations on all 3 consecutive days and another arena had the highest levels during all 3 days. The mean and median values were higher on the second and third day in most arenas due to longer use of resurfacing and ice-edger machines on the second or third day. The mean indoor concentrations were $>20$-fold higher than the mean outdoors when propane-powered resurfacing machines had been used. The highest $\mathrm{NO}_{2}$ concentrations in the electric arenas were similar to the lowest in the propane arenas. Outdoor $\mathrm{NO}_{2}$ concentrations tended to be similar to those inside the electric arenas.

\section{Respiratory symptoms and allergic disorders}

Overall, "ever asthma" was reported by $16 \%$ of the children and physician-diagnosed asthma by $14 \%$. Asthma medication in the past year was used by $16 \%$. Male children tended to have a higher prevalence of "ever asthma" (M=16\%, $\mathrm{F}=11 \%)$ and physiciandiagnosed asthma $(M=18 \%, F=9 \%)$. Signs of lower and upper respiratory allergic disease, "ever asthma", physician-diagnosed asthma and asthma medication in the past year were as prevalent in the group of children attending ice arenas with propane-powered machines as in the group of children attending ice arenas with electric machines (table 3). Most children with "ever asthma" had their onset of asthma before starting hockey training or figure skating in ice arenas (63\% attending propane arenas, $58 \%$ attending electric arenas). When these children were excluded there was still no difference in symptom prevalence between the two exposure groups. Remission of asthma, expressed as "ever asthma" but without current symptoms of asthma and/or asthma medication during the past year, was also similar among children practising in electric arenas $(16 \%)$ and in propane arenas $(13 \%)$.

In order to further assess the effect of $\mathrm{NO}_{2}$ exposure, children who had attended propane arenas were divided into two exposure groups based on the results of the $\mathrm{NO}_{2}$ measurements (table 4). Four of the propane arenas had $\mathrm{NO}_{2}$ concentrations above the median of $\mathrm{NO}_{2}$ (mean $510 \mu \mathrm{g} \cdot \mathrm{m}^{-3}$, median $396 \mu \mathrm{g} \cdot \mathrm{m}^{-3}$ ). The remaining nine arenas had a mean

Table 3. - Odds ratios (OR) and percentages for symptoms of asthma and rhinitis among children attending ice arenas using propane-powered resurfacing machines in relation to children from arenas using electric-powered machines

\begin{tabular}{|c|c|c|c|}
\hline & Propane & Electric & $\mathrm{OR}^{\#}(95 \%$ confidence interval $)$ \\
\hline \multicolumn{4}{|l|}{ Asthma } \\
\hline Wheezing ever & $183(18.9)$ & $121(21.4)$ & $0.9(0.7-1.1)$ \\
\hline Wheezing 12 months & $127(13.1)$ & 83 (14.6) & $0.9(0.7-1.2)$ \\
\hline Exercise wheeze & $103(10.6)$ & $76(13.4)$ & $0.8(0.6-1.1)$ \\
\hline Asthma ever & 144 (14.9) & $96(17.0)$ & $0.9(0.7-1.2)$ \\
\hline Asthma diagnosed by physician & $133(13.7)$ & $84(14.8)$ & $1.0(0.7-1.3)$ \\
\hline Asthma medication 12 months & $148(15.3)$ & $95(16.8)$ & $0.8(0.5-1.3)$ \\
\hline \multicolumn{4}{|l|}{ Rhinitis $^{\bullet}$} \\
\hline Nose symptoms ever & $251(26.0)$ & $158(27.8)$ & $0.9(0.7-1.1)$ \\
\hline Nose symptoms 12 months & $214(22.1)$ & $142(25.1)$ & $0.9(0.7-1.1)$ \\
\hline
\end{tabular}

Data are presented as n (\%) unless otherwise stated. ${ }^{*}$ : OR adjusted for parental history of asthma or atopy and sex; ${ }^{\top}$ : nose symptoms without upper respiratory infection. 
Table 4.- Odds ratios (OR) and percentages for symptoms of asthma and rhinitis among children attending arenas using propane-powered resurfacing machines with high (mean $\left.510 \mu \mathrm{g} \cdot \mathrm{m}^{-3}\right)$ concentrations of nitrogen dioxide $\left(\mathrm{NO}_{2}\right)$ in relation to children from such arenas with low (mean $89 \mu \mathrm{g} \cdot \mathrm{m}^{-3}$ ) concentrations

\begin{tabular}{|c|c|c|c|}
\hline & High $\mathrm{NO}_{2}$ & Low $\mathrm{NO}_{2}$ & $\mathrm{OR}^{\#}(95 \%$ confidence interval $)$ \\
\hline \multicolumn{4}{|l|}{ Asthma } \\
\hline Wheezing ever & $90(21.4)$ & $87(16.2)$ & $1.4(1.0-1.9)$ \\
\hline Wheezing 12 months & $61(14.5)$ & $63(11.7)$ & $1.2(0.8-1.8)$ \\
\hline Exercise wheeze & $49(11.7)$ & $51(9.5)$ & $1.2(0.8-1.9)$ \\
\hline Asthma ever & 71 (16.9) & 69 (12.9) & $1.4(0.9-2.0)$ \\
\hline Asthma diagnosed by physician & $66(15.7)$ & $63(11.7)$ & $1.4(0.9-2.0)$ \\
\hline Asthma medication 12 months & $68(16.2)$ & $76(14.2)$ & $1.2(0.8-1.7)$ \\
\hline \multicolumn{4}{|l|}{ Rhinitis } \\
\hline Nose symptoms ever & $130(30.9)$ & $114(21.3)$ & $1.7(1.3-2.3)$ \\
\hline Nose symptoms 12 months & $114(27.2)$ & $97(18.1)$ & $1.7(1.2-2.4)$ \\
\hline
\end{tabular}

Data are presented as n (\%) unless otherwise stated. ${ }^{*}$ : odds ratios adjusted for parental history of allergic disease and sex; ${ }^{\circ}$ : nose symptoms without upper respiratory infection.

concentration of $89 \mu \mathrm{g} \cdot \mathrm{m}^{-3}$ and a median concentration of $65 \mu \mathrm{g} \cdot \mathrm{m}^{-3}$. Thirteen subjects attended propane arenas without known concentrations of $\mathrm{NO}_{2}$ and are excluded from this subanalysis. Nasal symptoms, without upper respiratory infection and "ever wheeze" were more prevalent among children with high exposure levels of $\mathrm{NO}_{2}$. There was also a tendency to increased prevalence of "ever asthma", physiciandiagnosed asthma and symptoms of asthma in the high exposure group. The onset of asthma before beginning to attend ice arenas regularly was similar in the two exposure groups (low 63\%, high 62\%). There was no significant difference in years of indoor hockey activities, training intensity and/or potential risk factors for development of atopic disease among children in the high and low $\mathrm{NO}_{2}$-exposure groups.

The study area mainly consisted of small communities and rural areas except for the city of Gävle. To minimise potential effects of other sources of air pollution, further analysis was made after exclusion of the 102 children exercising in the two electric arenas in Gävle. However, the results remained unchanged. The present study was conducted during February and March, i.e. before the pollen season. Exclusion of children reporting symptoms related to furred pets and/or pollen also did not change the results.

\section{Discussion}

In this study there was no difference in the prevalence of asthma among children playing hockey or figure skating in ice arenas with propane-powered ice-resurfacing machines compared to children in ice arenas with electric machines, despite high exposure to $\mathrm{NO}_{2}$ during several years in the former group. However, there appeared to be a difference within the group of children attending ice arenas using propane-powered resurfacing machines. Among children exposed to very high concentrations of $\mathrm{NO}_{2}$, upper respiratory symptoms and "ever wheeze" were more common compared to children exposed to lower concentrations, suggesting an exposure-response relationship.

Inhalation of extremely high concentrations of
$\mathrm{NO}_{2}$ can induce toxic pneumonitis and pulmonary oedema. Controlled exposure studies show an increased bronchial hyperresponsiveness in normal subjects at concentrations $>2,000 \mu \mathrm{g} \cdot \mathrm{m}^{-3}$ and $>200 \mu \mathrm{g} \cdot \mathrm{m}^{-3}$ in asthmatics $[6,11]$. However, little is known about the impact of frequent, short-term exposure to high concentrations of $\mathrm{NO}_{2}$. In the present study of ice arenas, $\mathrm{NO}_{2}$ concentrations ranged from $29-1,015 \mu \mathrm{g} \cdot \mathrm{m}^{-3}$ (mean $276 \mu \mathrm{g} \cdot \mathrm{m}^{-3}$ ), and concentrations of the same magnitude of $\mathrm{NO}_{2}$ have been reported by others [6, 7]. The wide range of concentrations could probably be explained by differences in ventilation systems, type and function of catalytic converter, size of the arena and activity on the ice.

The prevalence of "ever asthma" was 16\% compared to $10.8 \%$ in a Swedish part of the ISAAC study investigating 13-14-yr-olds [12]. Conversely, symptoms of asthma and rhinitis were not more frequent than in the ISAAC study. Exercise is an important provoking factor for asthma in individuals with bronchial hyperreactivity. Physically active children may have an increased perception or awareness of respiratory symptoms, which may explain the high prevalence of asthma in the present study. Sports are often recommended in asthmatic children as one of the cornerstones in asthma treatment. This may contribute to the high prevalence of asthma among athletic children also shown by other investigators [13]. However, the increase of the asthma prevalence in the present study could also be due to a true increase of the asthma occurrence among children attending ice arenas. Recently, several studies have indicated a relationship between athletics and asthma. Thirty one per cent of Swedish elite cross-country skiers have exercise-induced asthma [14]. In a Swiss study, it was demonstrated that ice hockey players had higher prevalence of asthma and bronchial hyperresponsiveness than floor ball players [15]. An American investigation involving 121 elite ice skaters showed exercise-induced bronchoconstriction in $35 \%$ of the skaters [16]. However, neither of the two latter studies presented objective measurements on air quality. It was suggested that exercising on ice at temperatures $\sim 5-10^{\circ} \mathrm{C}$, compared to training at higher temperatures, could induce bronchial hyperresponsiveness. 
Questionnaire-based information on prevalence is widely used in asthma epidemiology in combination with cross-sectional methodology. This design has disadvantages related to control of certain types of bias, such as recall bias. Conversely, the question on "physician diagnosed asthma" is shown to have very high specificity, near $100 \%$, and a sensitivity of about $70 \%$ in a study with similar design and age group [17]. However, a poor sensitivity has less effect on the estimation of OR than poor specificity of the health outcome assessment [18].

Selection bias could contribute to the lack of difference in symptom prevalence between propane arenas and electric arenas. The insurance file that was used to identify study subjects only registered children from the age of 10 when they become licensed players in Sweden. Consequently, children who stopped hockey or figure skating before that age were not included and some children may have experienced more discomfort in the propane arenas and quit or changed sports before the age of ten. The fact that children in electric arenas showed a tendency to report more atopy and parental atopy supports this hypothesis. Furthermore, it is possible that some children in the electric-arena group had regular activities in propane arenas during tournaments and matches, contributing to a smaller exposure contrast and difficulties in detecting exposure-related differences in health outcomes.

In conclusion, children with $>3$ yrs of frequent exposure to very high concentrations of nitrogen dioxide in ice arenas using propane-powered iceresurfacing machines did not have a higher prevalence of asthma or rhinitis than children in ice arenas using electric resurfacing machines. However, children exposed to the highest concentrations of nitrogen dioxide had more respiratory symptoms, particularly nasal symptoms, than children exposed to lower concentrations. Furthermore, the overall prevalence of asthma appears high among children playing ice hockey.

\footnotetext{
Acknowledgements. The authors would like to thank M. Lewné for helping to conduct nitrogen dioxide measurements in the arenas and A. Bessö for helping with statistical questions.
}

\section{References}

1. Pershagen G, Rylander E, Norberg S, Eriksson M, Nordvall SL. Air pollution involving nitrogen dioxide exposure and wheezing bronchitis in children. Int J Epidemiol 1995; 24: 1147-1153.

2. Wjst M, Reitmeir P, Dold S, et al. Road traffic and adverse effects on respiratory health in children. $B M J$ 1993; 307: 596-600.

3. Kramer U, Koch T, Ranft U, Ring J, Behrendt H. Traffic-related air pollution is associated with atopy in children living in urban areas. Epidemiology 2000; 11: 64-70.

4. Hirsch T, Weiland SK, von Mutius E, et al. Inner city air pollution and respiratory health and atopy in children. Eur Respir J 1999; 14: 669-677.

5. van Vliet $P$, Knape $M$, de Hartog J, Janssen $N$, Harssema H, Brunekreef B. Motor vehicle exhaust and chronic respiratory symptoms in children living near freeways. Environ Res 1997; 74: 122-132.

6. Brauer M, Lee K, Spengler JD, et al. Nitrogen dioxide in indoor ice skating facilities: An international survey. J Air Waste Manag Assoc 1997; 47: 1095-1102.

7. Hedberg K, Hedberg CW, Iber C, et al. An outbreak of nitrogen dioxide-induced respiratory illness among ice hockey players. JAMA 1989; 262: 3014-3017.

8. Karlson-Stiber C, Hojer J, Sjoholm A, Bluhm G, Salmonson H. Nitrogen dioxide pneumonitis in ice hockey players. J Intern Med 1996; 239: 451-456.

9. Asher MI, Keil U, Anderson HR, et al. International Study of Asthma and Allergies in Childhood (ISAAC): rationale and methods. Eur Respir J 1995; 8: 483-491.

10. Ferm M, Svanberg P-A. Cost-efficient techniques for urban and background measurements of $\mathrm{SO}_{2}$ and $\mathrm{NO}_{2}$. Atmosph Environt 1998; 32: 1377-1381.

11. Horstman DH, Ball BA, Brown J, Gerrity T, Folinsbee LJ. Comparison of pulmonary responses of asthmatic and nonasthmatic subjects performing light exercise while exposed to a low level of ozone. Toxicol Ind Health 1995; 11: 369-385.

12. Bjorksten B, Dumitrascu D, Foucard $\mathrm{T}$, et al. Prevalence of childhood asthma, rhinitis and eczema in Scandinavia and Eastern Europe. Eur Respir $J$ 1998; 12: 432-437.

13. Nystad W, Magnus P, Roksund O, Svidal B, Hetlevik $\mathrm{O}$. The prevalence of respiratory symptoms and asthma among school children in three different areas of Norway. Pediatr Allergy Immunol 1997; 8: 35-40.

14. Larsson K, Tornling G, Gavhed D, Muller-Suur C, Palmberg L. Inhalation of cold air increases the number of inflammatory cells in the lungs in healthy subjects. Eur Respir J 1998; 12: 825-830.

15. Leuppi JD, Kuhn M, Comminot C, Reinhart WH. High prevalence of bronchial hyperresponsiveness and asthma in ice hockey players. Eur Respir J 1998; 12: 13-16.

16. Mannix ET, Farber MO, Palange P, Galassetti P, Manfredi F. Exercise-induced asthma in figure skaters. Chest 1996; 109: 312-315.

17. Ronmark E, Jonsson E, Platts-Mills T, Lundback B. Different pattern of risk factors for atopic and nonatopic asthma among children. Allergy 1999; 54: 926-935.

18. Pershagen G. Challenges in epidemiologic allergy research. Allergy 1997; 52: 1045-1049. 